\title{
Statyba
}

\section{PLAZMA ARC JOINING OF THIN PLATE CONSTRUCTIONS}

\section{A. V. Valiulis}

To cite this article: A. V. Valiulis (1995) PLAZMA ARC JOINING OF THIN PLATE

CONSTRUCTIONS, Statyba, 1:1, 76-82, DOI: 10.1080/13921525.1995.10531503

To link to this article: https://doi.org/10.1080/13921525.1995.10531503

曲 Published online: 26 Jul 2012.

Submit your article to this journal $2 \pi$

III Article views: 39 


\section{PLAZMINIS PLONALAKŠČIŲ KONSTRUKCLJŲ SUJUNGIMAS}

\section{A.V.Valiulis}

\section{Irvadas}

Plonasieniai gaminiai (talpos, silfonai, ekranai ir kt.) dažnai suvirinami mikroplazminiu būdu, naudojant argono ar argono ir deguonies, vandenilio bei kitu duju mixiniu plazmą. Plonasienius $(0,05-0,1 \mathrm{~mm})$ gaminius sunku suvirinti sandūriniu būdu. Tokiems sujungimams labiau tinka galinès ar atriestinès siūlès. Šios rū̌ies siūlès skiriasi nuo sandūriniy siūliu savo geometrine forma, šilumos tekéjimu kristalizacijos metu, didelio ploto skysto metalo sąlyčiu su dujine faze. Sujungimo stiprumui ir siūlès metalo kokybei turi ịtakos siūlès geometrija ir pirminè metalo struktūra. Šie parametrai labai jautrūs suvirinimo režimo pokyčiams ir gali būti valdomi. Kristalizacijos pobūdis valdo grūdeliụ formą ir dydị, mikrostruktūrą, segregaciju kieki, intarpu pasiskirstymą, akytumą, itrūkimu susidarymą ir tokiu būdu siūlès metalo savybes.

\section{Siülès geometrija ir ją sąlygojantys veiksniai}

Pastaruoju metu yra nustatyta, kad kristalizacijos parametrai, kurie kontroliuoja siūlès vonelès metalo kristalizacijos eigą - temperatūros gradientas, kristaly augimo greitis, tarpfazinis peraušimas, labai koreliuoja su siūlès metalo mikrostruktūra.

Suvirinant galines siūles, vonelès aukštis ir jos plotis yra susiję. Keičiantis siūlès pločiui, siūlès rumbelè asimptotiškai auga, kol pasiekia tam tikrą aukštị. Siūlès plotis, kintant suvirinimo parametrams, keičiasi labai nedaug, nors islydyto metalo vonelès tūris gali būti pakitęs labai žymiai. Vonelès aukštị, esant sąlyčio su pagrindiniu metalu kampui lygiam $\pi / 2$, galima apskaičiuoti pagal formulę:

$$
h^{\prime}=[h /(2 \gamma / \rho \cdot g)]^{1 / 2}=1
$$


Jei skysto lydinio lydymosi temperatūroje $\left(1455^{\circ} \mathrm{C}\right.$ ) paviršinis ịtempimas $\gamma=1,796 \mathrm{~N} / \mathrm{m}$, skysto metalo tankis $\rho=7,69 \cdot 10^{3} \mathrm{~kg} / \mathrm{m}^{3}$, tuomet:

$$
h=1[2 \gamma /(\rho \cdot g)]^{1 / 2}
$$

Iš čia:

$$
\begin{gathered}
h=1\left[2 \cdot 1,796 / 7,69 \cdot 10^{3} \cdot 9,81\right]^{1 / 2}=0,00689 \mathrm{~m} \\
\operatorname{arba} \quad h=6,9 \mathrm{~mm}
\end{gathered}
$$

Skysto metalo paviršinio įtempimo dydis priklauso nuo temperatūros ir, jai didejjant, mažéja. Laikant, kad viršutinèje vonelès dalyje, anodinès dèmes zonoje metalo temperatūra yra $1900{ }^{\circ} \mathrm{C}$, paviršinis itempimo dydis bus:

$$
\gamma=1796-0,35(t-1455) \mathrm{nN} / \mathrm{m}
$$

tuomet skystos vonelès aukštis būtu $h=6,58 \mathrm{~mm}$.

Suvirintų bandinių siūlių matavimai rodo, kad suvirinant $0,4 \mathrm{~mm}$ storio metalą vonelès aukštis yra $0,5-0,65 \mathrm{~mm}$. Padidinus metalo storị, t.y. vonelès plotị iki $0,8 \mathrm{~mm}$, vonelès aukštis padidèja iki $0,82 \mathrm{~mm}, 1 \mathrm{~mm}$ pločio vonelès turi $0,88-1,0 \mathrm{~mm}$ aukštị. Prieštaravimai tarp matuojamo ir skaix̌iuojamo dydžiu yra labai dideli ir negali būti tik dvimačio skaiciavimo modelio netikslumas.

Matuojant mikroplazminiu suvirinimu gauty galiniụ siūliụ geometriją, nustatytas suvirinamo gaminio storio ir siūlès aukščio santykio koreliacinis koeficientas:

$$
k_{s}=40+\left(1-S_{B}\right) \cdot 100
$$

čia $S_{B}$ - suvirinamo metalo storis, $\mathrm{mm}$.

Lygti papildžius koreliaciniu koeficientu $k_{s}$ :

$$
h^{\prime}=\left[h /\left(2 \gamma /\left(\rho \cdot g \cdot k_{s}\right)\right)\right]^{1 / 2}=1
$$

ir apskaixiavus siūlès aukštị $h$ matyti, kad eksperimento keliu gautų siūliụ aukštis nedaug skiriasi nuo aukščio gauto skaičiavimo bũdu (1 lentelè). 
1 lentelè. Skaičiavimais ir eksperimentais nustatyto galinès siūlès aukšcio palyginimas

\begin{tabular}{|c|c|c|}
\hline \multirow{2}{*}{$\begin{array}{c}\text { Metalo storis } \\
\mathrm{mm}\end{array}$} & Galinès siūlés aukštis, mm \\
\cline { 2 - 3 } & Išmatuotas eksperimentu & Apskaixiuotas \\
\hline 0,4 & $0,50 \ldots ., 0,65$ & 0,630 \\
0,6 & $0,68-0,72$ & 0,707 \\
0,8 & $0,82 \ldots 0,83$ & 0,836 \\
1,0 & $0,93-1,06$ & 1,00 \\
\hline
\end{tabular}

Mažo storio galiniu siūlių aukštis $20-30 \%$ didesnis už suvirinamo metalo storị. Didéjant storiui క̌s skirtumas mažèja. Suvirinant $1,0 \mathrm{~mm}$ storio gaminius siūlès aukštis apytiksliai lygus gaminio storiui.

Suvirinimo vonelès gylis gali būti apskaičiuotas žinant išlginę suvirinimo energiją ir fizikines suvirinamo metalo savybes (šiluminị laidumą, tūrinę specifinę šilumą) pagal Z.Rozenthalio [1], N.Rikalino [2] Šlumos sklidimo metaluose lygti.

Ploniems metalams temperatūros/laiko kitimo išraiška, veikiant judančiam pastoviu greičiu Silumos Šaltiniui, bendruoju pavidalu yra:

$$
T=T_{0}+\frac{q / v}{d(4 \cdot \pi \cdot \lambda \cdot \rho \cdot c \cdot t)^{1 / 2}} \exp \frac{t^{2}}{4 a t}
$$

Čia $q / v-$ išiginè suvirinimo energija, $\lambda$ - Šiluminis laidumas, $a-$ temperatūrinis laidumas, $\rho \cdot c$ - tūriné Šiluminè talpa, $t$ - aplinkos (pašildymo) temperatūra, $d$ - suvirinamo gaminio storis.

Suvirinant plonus metalus mažo skerspjūvio ploto ir išlydyto metalo tūrio siūlèmis, metalo vonelès gyliui turès pastebimą ịtaką slaptoji lydimosi šiluma. Kai metalo vonelè formuojasi, plazmos energija yra absorbuojama kaip slaptoji lydymosi šiluma. Nors ši šluma vèliau, kristalizacijos metu, yra išskiriama, lydymosi metu ji paimama iš energijos Saltinio ir saugoma skystame metale. Tokiu büdu skaiciuojant išlydyto metalo gylì, ši šilumos kiekị reikia minusuoti. Jei suvirinimo vonelè yra aproksimuota kaip pusẻ cilindro turinčio spinduli $z_{m}$, tuomet, kai efektyvinès energijos ivvedimas yra $q^{\prime}$, tai išlydomo metalo tūris per sekundę yra:

$$
\begin{gathered}
\pi \cdot z_{m}^{2} \cdot v / 2 . \\
q^{\prime}=q-\frac{\pi z_{m}^{2} v \cdot L}{2} .
\end{gathered}
$$


Čia $L$ - slaptoji lydymosi šluma tūrio vienetui, $v$ - energijos Šaltinio judejimo greitis. Aukščiausia temperatūra $T_{p}$, pasiekiama bet kuriame kaitinamo metalo taške žemiau jo paviršiaus $z_{0}$, yra apskaičiuojama pagal redukuotą Z.Rozenthalio [1] pateikiamą formulę:

$$
T_{p}=T_{0}+\frac{2}{\pi \cdot e} \cdot \frac{q / v}{\rho \cdot c\left(z+z_{0}\right)^{2}}
$$

Čia $T_{0}$ - metalo temperatūra prieš suvirinimą, $e$ - natūrinio logaritmo pagrindas, $e=2,718, q / v-$ išilginè energija, $\rho \cdot c$ - tūrinè šiluminè talpa, $z$ - atstumas nuo vonelès paviršiaus (gylis).

Istačius lygties (7) $q^{\prime}$ reikšmę i lygties (8) $q$ ir $T_{p}$ prilyginus $T_{m}$ - metalo lydymosi temperatūrai, galima apskaičiuoti išlydomo metalo vonelès gyli $z_{m}$.

Skaiciavimo rezultatai labai artimi eksperimentu duomenims (2 lentelè).

2 lentelè. ISilginès energijos ịtaka išlydomos vonelès gyliui

\begin{tabular}{|c|c|c|c|c|c|}
\hline \multicolumn{3}{|c|}{ Suvirinimo parametrai } & \multicolumn{2}{c|}{ Vonelès gylis $\mathrm{mm}$} \\
\hline$I_{s}$ & $V_{s}$ & $q$ & $U$ & $\begin{array}{c}\text { Nustatytas } \\
\text { eksperimentu }\end{array}$ & $\begin{array}{c}\text { Apskaixiuotas } \\
A\end{array}$ \\
$m / s$ & $J / s$ & $V$ & $z_{m}$ \\
\hline 25 & $5,83 \cdot 10^{-3}$ & 250 & 10 & $0,88-0,93$ & 0,9 \\
3 & $1,39 \cdot 10^{-3}$ & 30 & 10 & 6,25 & 0,63 \\
3 & $0,8 \cdot 10^{-3}$ & 30 & 10 & 1,07 & 1,22 \\
\hline
\end{tabular}

Svarbiausieji veiksniai lemiantys vonelès skerspjūvio formą yra vonelès plotis ir jos skerspjüvio plotas (1, 2 ir 3 pav.).

Vonelès skerspjūvio plotas nedimensine išraiška yra:

arba

$$
\begin{gathered}
A^{\prime}=A /(2 \gamma / \rho \cdot g), \\
A^{\prime}=\left[h^{\prime}+\frac{1-\cos \theta}{h^{\prime}}\right] \frac{B^{\prime}}{2}-\sin \theta, \\
B^{\prime}=[B /(2 \gamma / \rho g)]^{1 / 2} .
\end{gathered}
$$

Skysto/kieto metalu sąlyčio kampas $\Theta$ yra nepriklausomas kintamasis. Jis nesusijęs su suminiu paviršiniu jẻgu veikimu. 


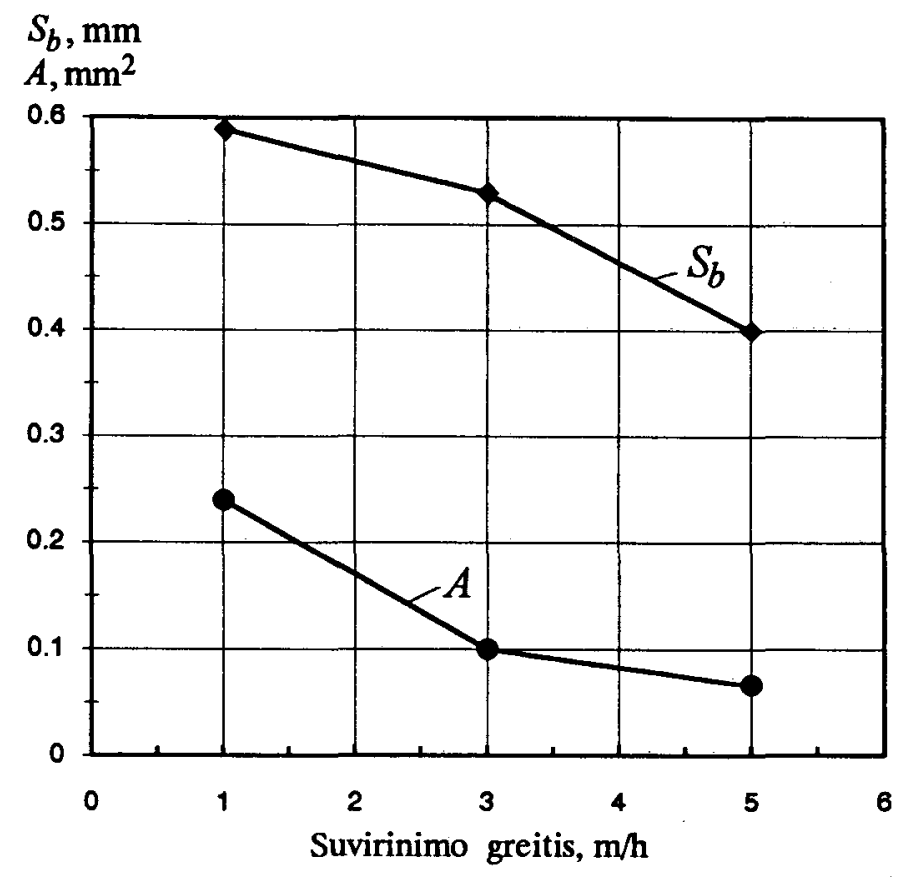

1 pav. Suvirinimo greičio ịtaka ił̌ilginès galinès siūlès geometriniams parametrams: $A$ - siūlès skersplotis; $S_{b}$ - siūlès plotis. Suvirimo režimas: srovẻ $3 \mathrm{~A}$, plazmoos duju iseiga 0,0072 $\mathrm{m}^{3} / \mathrm{h}$, apsauginiu duju išeiga $0,24 \mathrm{~m}^{3} / \mathrm{h}$, lanko ilgis $2 \mathrm{~mm}$, metalo storis $0,4 \mathrm{~mm}$

Vonelès plotis (1 pav.) yra nepriklausomas nuo suvirinimo režimo ir gali büti išmatuotas tiksliai. Skerspjūvio plotas lygus išlydyto metalo tũriui padalintam iš suvirinimo greicio $v_{s}:$

$$
A=b / \rho \cdot v_{s}
$$

Tuo pat metu siūlès aukštis bus susijęs tik su kontaktinio kampo $\theta$ dydžiu ir siūlès vonelès paviršiaus kreiviu $R_{0}$. Taigi žinant išlydomo metalo kiekị, išilginę šiluminę energiją ir suvirinimo greitị galima apskaičiuoti galinès siūlès profilį.

Skysto metalo paviršinis įtempimas yra temperatūros funkcija:

$$
\gamma_{t}=\gamma_{m}+(d \gamma / d t) \cdot\left(T-T_{m}\right)
$$

Čia $\gamma_{t}$ - metalo paviršinis îtempimas ịkaitinimo temperatūroje, $\gamma_{m}$ - metalo paviršinis ittempimas lydymosi temperatūroje, $T$ - metalo paviršiaus temperatūra, $T_{m}$ - metalo lydymosi temperatūra ${ }^{\circ} \mathrm{C}$.

Paviršinio îtempimo arba pavirక̌inès energijos skirtumas tarp "צaltos" ir "karštos" vonelès pavirక̌iaus srities siekia $\Delta \gamma=-156 m \mathrm{~N} / \mathrm{m}$. Minuso ženklas reiškia, kad paviršinio ịtempimo jègos temps metalą iš vonelès viršaus $\mathfrak{i}$ apačią ir taip metalo vonelèje atsiras Marangoni tekèjimas, tai yra metalo tekéjimas sukeltas termokapiliariniu jègu. 


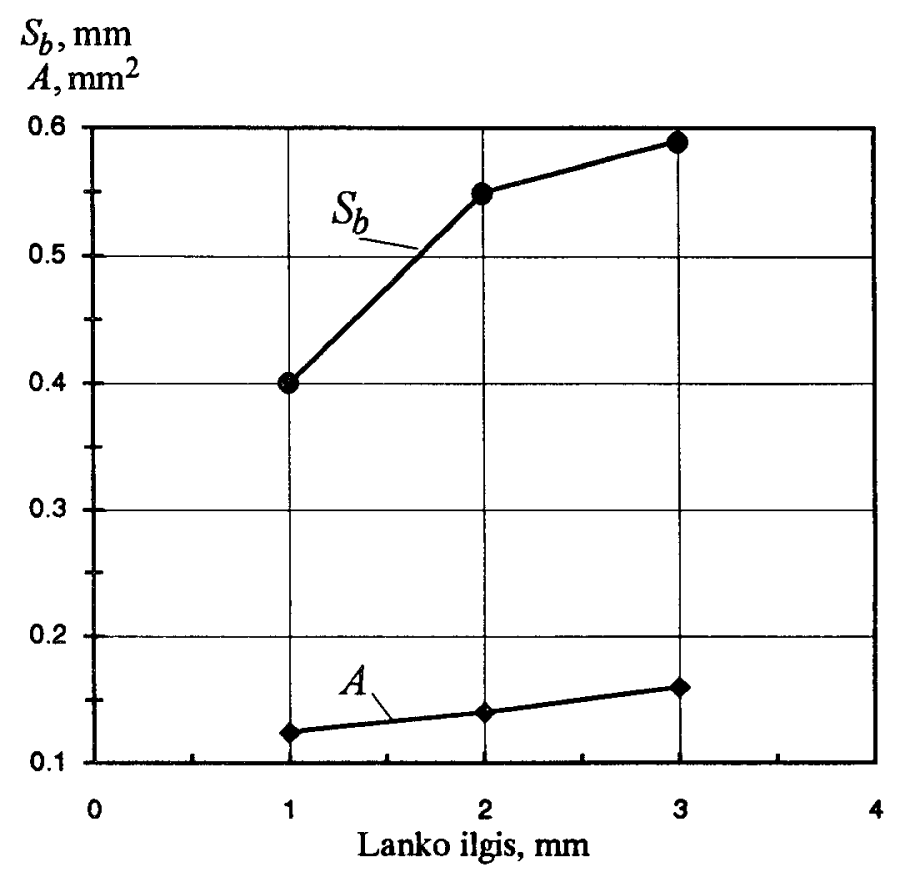

2 pav. Lanko ilgio ịtaka išilginès galinès siūlès geometriniams parametrams. Suvirinimo greitis $5 \mathrm{~m} / \mathrm{h}$, kiti parametrai kaip 1 pav.

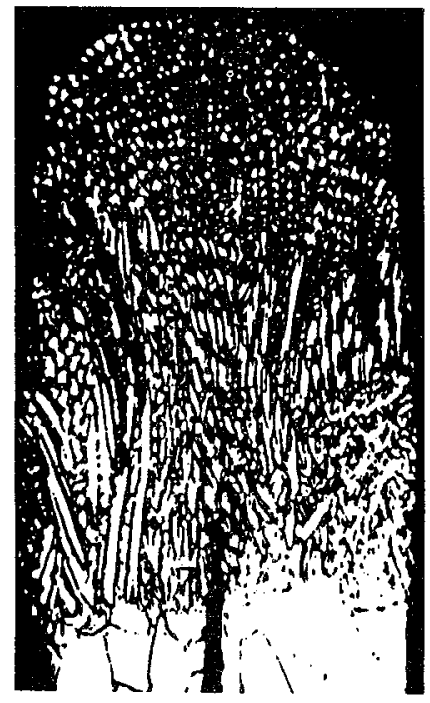

a

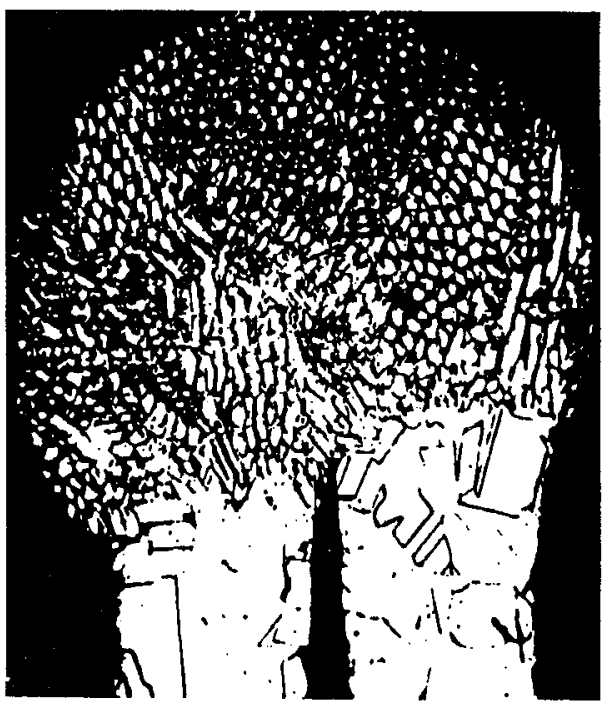

b

3 pav. Lanko ilgio jtaka siülès geometrijai ir mikrostruktūrai, $\times 100$. Suvirinimo greitis $5 \mathrm{~m} / \mathrm{h}$, kiti parametrai kaip 1 pav.: $a$ - lanko ilgis - $1 \mathrm{~mm}, b$ - lanko ilgis $2 \mathrm{~mm}$ 
Galinẻs siūlès skysto metalo vonelè yra mažo skerspjūvio ploto ir nedidelès masès. Yonelè geometrine forma šiek tiek panaši i metalo lašą susidaranti lydantis elektrodui. Diď̌iausią panašumą i lašą turi vonelès sonai, o išilgine kryptimi vonelè yra panašesnè i normalią lankinio suvirinimo vonelę. Tiriant metalo tekejjimą laše yra nustatyta [3], kad termokapiliarinès jègos sukuria $\mathfrak{i}$ išorę nukreiptą metalo tekèjimą. Skystos fazès tekèjimo kryptis ir charakteris priklauso tik nuo termokapiliariniu jègu veikimo, bet nepriklauso nuo sunkio jègos. Atlikti tyrimai rodo, kad ir žemutinèje padètyje esančioje vonelèje metalo tekejjimą lems ne sunkio jègų, o termokapiliarinių, elektromagnetinio maišymo ir lanko plazmos aerodinaminio veikimo jègos.

\section{LTTERATŨRA}

1. Nishiguchi K., Ohij T., Matsui H. Study of bead surface profile. IIW Documment 212391-77.1977.

2. Rosental D. Transactions Amer. Soc. of Metals, 1946, Vol. 68, p. 849.

3. Rykalin N., Uglov A., Kokora A. Laser machining and welding. Pergamon Press, Oxford. 1978.

4. Ishizaki K. Journ. Jpn. Weld. Soc., 1965, 34(2), 146.

\section{PLAZMA ARC JOINING OF THIN PLATE CONSTRUCTIONS}

\section{A.V.Valiulis}

S u m mary

Heat and fluid flow exist not only in ingots or big size welds but also in small size microplasma arc melted weld pool. Edge weld pool geometry depend from interfacial energy, direction of the fluid flows in the weld pool caused by thermocapilary convection. Thermocapilary convection is the dominant flow mechanism under downhand welding conditions. Comparision are made between calculated size of edge weld and experimental results. 